\title{
The incidence of acute myocardial infarction
} after elective spinal fusions or joint replacement surgery in the United States: a large-scale retrospective observational cohort study in 322,585 patients

Post-surgical myocardial infarction data

Patrick J. Arena', Jingping Mo², Qing Liư ${ }^{3}$, Xiaofeng Zhou', Richard Gong ${ }^{4}$, Charles Wentworth', Sundaresan Murugesan ${ }^{4}$ and Kui Huang ${ }^{1 *}$

\begin{abstract}
Background: Acute myocardial infarction (AMI) is an uncommon but fatal complication among patients undergoing elective spinal fusion surgery (SF), total hip arthroplasty (THA), and total knee arthroplasty (TKA). Our objective was to estimate the incidence of AMl among adults undergoing elective SF, THA, and TKA in different post-operative risk windows and characterize high-risk sub-populations in the United States.
\end{abstract}

Methods: A retrospective cohort study was conducted using data from a longitudinal electronic healthcare record (EHR) database from January 1, 2007 to June 30, 2018. ICD codes were used to identify SF, THA, TKA, AMI, and selected clinical characteristics. Incidence proportions (IPs) and 95\% confidence intervals were estimated in the following risk windows: index hospitalization, $\leq 30, \leq 90, \leq 180$, and $\leq 365$ days post-operation.

Results: A total of 67,533 SF patients, 87,572 THA patients, and 167,480 TKA patients were eligible for the study. The IP of AMI after SF, THA, and TKA ranged from $0.36,0.28$, and $0.25 \%$ during index hospitalization to $1.05,0.93$, and $0.85 \% \leq 365$ days post-operation, respectively. The IP of AMI was higher among patients who were older, male, with longer hospital stays, had a history of AMI, and had a history of diabetes.

Conclusion: The IP of post-operative AMI was generally highest among the SF cohort compared to the THA and TKA cohorts. Additionally, potential high-risk populations were identified. Future studies in this area are warranted to confirm these findings via improved confounder control and to identify effect measure modifiers.

Keywords: Myocardial infarction, Spinal fusion, Total hip arthroplasty, Total knee arthroplasty, Epidemiology, Electronic healthcare records

*Correspondence: Kui.A.Huang@pfizer.com

${ }^{1}$ Global Medical Epidemiology \& Big Data Analysis, Pfizer Inc., 235 E 42nd St, New York, NY 10017, USA

Full list of author information is available at the end of the article

\section{Background}

Cardiovascular disease (CVD) is one of the top causes of morbidity and mortality globally [1]. Within the United States (US), the 2019 Heart Disease and Stroke Statistics report from the American Heart Association concluded

(c) The Author(s) 2021. Open Access This article is licensed under a Creative Commons Attribution 4.0 International License, which permits use, sharing, adaptation, distribution and reproduction in any medium or format, as long as you give appropriate credit to the original author(s) and the source, provide a link to the Creative Commons licence, and indicate if changes were made. The images or other third party material in this article are included in the article's Creative Commons licence, unless indicated otherwise in a credit line to the material. If material is not included in the article's Creative Commons licence and your intended use is not permitted by statutory regulation or exceeds the permitted use, you will need to obtain permission directly from the copyright holder. To view a copy of this licence, visit http://creativecommons.org/licenses/by/4.0/. The Creative Commons Public Domain Dedication waiver (http://creativeco mmons.org/publicdomain/zero/1.0/) applies to the data made available in this article, unless otherwise stated in a credit line to the data. 
that the prevalence of overall CVD (i.e., coronary heart disease, heart failure, stroke, and hypertension) in adults greater than 20 years of age was $48.0 \%$ (121.5 million Americans in 2016) [2]. Myocardial infarction (MI) is a key component to the burden of CVD [3]. Annually, over 800,000 people in the US experience an acute MI (AMI), of which $27 \%$ die [4].

Although AMI is an uncommon but fatal complication among elective surgical populations [5-7], the recognition of this adverse event is critical given the increased age of the population undergoing elective surgical procedures and the increased volume of surgeries in general. For example, recent research has shown that the frequency and utilization of spinal fusion (SF) have increased at a higher rate than other notable inpatient procedures (including laminectomy, percutaneous transluminal coronary angioplasty, and coronary artery bypass graft) over the period from 1998 to 2008 in the US; additionally, the authors found that the average age for SF increased over the study period [8]. Furthermore, an analysis of National Inpatient Sample (NIS) data from 2000 to 2014 determined that primary total hip arthroplasty (THA) is projected to grow $71 \%$ by 2030 and primary total knee arthroplasty (TKA) is projected to grow $85 \%$ by 2030 [9].

It is important to have background epidemiology data about post-operative AMI during various risk windows and among different sub-groups to contextualize safety data in clinical trials and the general population. This cohort study built on previous research [10], and it was designed to estimate the incidence of AMI among adults undergoing elective SF, THA, or TKA using a large electronic healthcare record (EHR) database in the US. The objectives of this study were to estimate the incidence of AMI among adults undergoing elective SF, THA, or TKA in different post-operative periods and to characterize high-risk sub-populations in the US.

\section{Methods Study design}

A retrospective cohort study of adults undergoing elective SF, THA, or TKA using Optum EHR, a longitudinal US EHR database, was performed. Optum EHR partners directly with several multi-specialty medical groups, integrated delivery networks, and hospital chains throughout the US to extract their EHR data. By normalizing, validating, and aggregating the de-identified data, the database generates a longitudinal view of patient care and captures a comprehensive collection of demographic, clinical, operational, and financial information. As of June 2018, Optum EHR reported having data on approximately 94.4 million unique patients. Furthermore, about $40 \%$ of the patient population was aged 50 years or older, with approximately $15 \%$ of patients 65 years of age or older. About one quarter of the patients had at least 6 years of observation time within the database.

The study period was January 1, 2007 to June 30, 2018 with a length of follow-up equating to 365 days. The index date was defined as the first date after January 1, 2007 that an adult had undergone an elective SF, THA, or TKA during the study period. To incorporate a 183day look-back window prior to the index surgery (for the purpose of obtaining medical history and excluding prevalent conditions as necessary), the earliest possible index surgical date was July 1,2007 . The latest index surgical date possible was June 30, 2017.

\section{Cohort formation}

Eligible patients were 18 to 85 years of age at the time of their first elective SF, THA, or TKA in the database. Furthermore, patients had 183 days of continuous enrollment within the database prior to their first elective SF, THA, or TKA (i.e., the baseline period) as well as this index surgery being performed on the day of admission to the healthcare facility or the day after admission. Elective SF, THA, and TKA (i.e., the exposures) were identified using the International Classification of Diseases (ICD), Ninth Revision, Procedure Classification System (ICD-9-PCS) codes listed in Table 1.

To select for a relatively healthy cohort that underwent inpatient elective surgeries, patients were excluded if they 1) underwent a major surgical procedure that occurred within 90 days prior to the index surgery; 2) had a surgical indication that was for an emergency procedure; 3 ) were pregnant; or 4) had cancer or end stage renal disease during the baseline period. AMI (i.e., the outcome) was defined based on the ICD, Ninth Revision, Clinical Modification (ICD-9-CM) codes listed in Table 2.

All ICD-9-PCS and ICD-9-CM codes were mapped to corresponding ICD, Tenth Revision (ICD-10) codes using General Equivalence Mapping techniques in order to account for the switch to ICD-10 coding in 2015.

\section{Data management and analysis}

All analyses were descriptive and conducted in SAS (version 9.4, SAS Institute, Cary, NC, USA). Descriptive statistics were performed to characterize the cohort in terms of demographic and clinical characteristics at the baseline. Patients were followed from the cohort entry index date until the occurrence of AMI, death, loss to follow-up, or end of study period, whichever occurred first.

IPs were defined as the number of new cases of AMI during each specified post-surgical time interval divided by the total (AMI-free) population at the start of each time interval. Crude IPs were calculated overall, and in the following stratifications: age, sex, race, 
Table 1 International Classification of Diseases (ICD), Ninth Revision, Procedure Classification System (ICD-9-PCS) codes used to define exposures

\begin{tabular}{|c|c|c|}
\hline Surgery Type & ICD-9-PCS Code & Code Description \\
\hline \multirow[t]{21}{*}{ Spinal fusion (SF) } & 81.01 & Atlas-axis spinal fusion \\
\hline & 81.02 & Other cervical fusion of the anterior column, anterior technique \\
\hline & 81.03 & Other cervical fusion of the posterior column, posterior technique \\
\hline & 81.04 & Dorsal and dorsolumbar fusion of the anterior column, anterior technique \\
\hline & 81.05 & Dorsal and dorsolumbar fusion of the posterior column, posterior technique \\
\hline & 81.06 & Lumbar and lumbosacral fusion of the anterior column, anterior technique \\
\hline & 81.07 & Lumbar and lumbosacral fusion of the posterior column, posterior technique \\
\hline & 81.08 & Lumbar and lumbosacral fusion of the anterior column, posterior technique \\
\hline & 81.31 & Refusion of atlas-axis spine \\
\hline & 81.32 & Refusion of other cervical spine, anterior column, anterior technique \\
\hline & 81.33 & Refusion of other cervical spine, posterior column, posterior technique \\
\hline & 81.34 & Refusion of dorsal and dorsolumbar spine, anterior column, anterior technique \\
\hline & 81.35 & Refusion of dorsal and dorsolumbar spine, posterior column, posterior technique \\
\hline & 81.36 & Refusion of lumbar and lumbosacral spine, anterior column, anterior technique \\
\hline & 81.37 & Refusion of lumbar and lumbosacral spine, posterior column, posterior technique \\
\hline & 81.38 & Refusion of lumbar and lumbosacral spine, anterior column, posterior technique \\
\hline & 81.39 & Refusion of spine, not elsewhere classified \\
\hline & 81.62 & Fusion or refusion of $2-3$ vertebrae \\
\hline & 81.63 & Fusion or refusion of 4-8 vertebrae \\
\hline & 81.64 & Fusion or refusion of 9 or more vertebrae \\
\hline & 84.51 & Insertion of interbody spinal fusion device \\
\hline \multirow[t]{10}{*}{ Total hip arthroplasty (THA) } & 00.70 & Revision of hip replacement, both acetabular and femoral components \\
\hline & 00.71 & Revision of hip replacement, acetabular component \\
\hline & 00.72 & Revision of hip replacement, femoral component \\
\hline & 00.73 & Revision of hip replacement, acetabular liner and/or femoral head only \\
\hline & 00.85 & Resurfacing hip, total, acetabulum and femoral head \\
\hline & 00.86 & Resurfacing hip, partial, femoral head \\
\hline & 00.87 & Resurfacing hip, partial, acetabulum \\
\hline & 81.51 & Total hip replacement \\
\hline & 81.52 & Partial hip replacement \\
\hline & 81.53 & Revision of hip replacement, not otherwise specified \\
\hline \multirow[t]{7}{*}{ Total knee arthroplasty (TKA) } & 00.80 & Revision of knee replacement, total (all components) \\
\hline & 00.81 & Revision of knee replacement, tibial component \\
\hline & 00.82 & Revision of knee replacement, femoral component \\
\hline & 00.83 & Revision of knee replacement, patellar component \\
\hline & 00.84 & Revision of total knee replacement, tibial insert (liner) \\
\hline & 81.54 & Total knee replacement \\
\hline & 81.55 & Revision of knee replacement, not otherwise specified \\
\hline
\end{tabular}

length of hospital stay, and selected clinical characteristics. IPs were also estimated in the following risk windows: index hospitalization (defined as the time interval from index surgery to discharge), $\leq 30$ days (i.e., 0 to 30 days), $\leq 90$ days (i.e., 0 to 90 days), $\leq 180$ days (i.e., 0 to 180 days), and $\leq 365$ days (i.e., 0 to 365 days) post-operation. For each post-operation period, incidence was calculated cumulatively; therefore, persons at risk and AMI events that were included in the preceding risk window were not excluded in the incidence calculation for the following risk window. All IPs were estimated with associated $95 \%$ confidence intervals (CIs), assuming a Poisson distribution.

Incidence rates were calculated as the number of new cases of AMI during each specified post-surgical time interval divided by the summed person-time of 
Table 2 International Classification of Diseases, Ninth Revision, Clinical Modification (ICD-9-CM) codes used to define acute myocardial infarction (AMI)

\begin{tabular}{ll}
\hline ICD-9-CM Code & Code Description \\
\hline 410.00 & Acute myocardial infarction of anterolateral wall, episode of care unspecified \\
410.01 & Acute myocardial infarction of anterolateral wall, initial episode of care \\
410.10 & Acute myocardial infarction of other anterior wall, episode of care unspecified \\
410.11 & Acute myocardial infarction of other anterior wall, initial episode of care \\
410.20 & Acute myocardial infarction of inferolateral wall, episode of care unspecified \\
410.21 & Acute myocardial infarction of inferolateral wall, initial episode of care \\
410.30 & Acute myocardial infarction of inferoposterior wall, episode of care unspecified \\
410.31 & Acute myocardial infarction of inferoposterior wall, initial episode of care \\
410.40 & Acute myocardial infarction of other inferior wall, episode of care unspecified \\
410.41 & Acute myocardial infarction of other inferior wall, initial episode of care \\
410.50 & Acute myocardial infarction of other lateral wall, episode of care unspecified \\
410.51 & Acute myocardial infarction of other lateral wall, initial episode of care \\
410.60 & True posterior wall infarction, episode of care unspecified \\
410.61 & True posterior wall infarction, initial episode of care \\
410.70 & Subendocardial infarction, episode of care unspecified \\
410.71 & Subendocardial infarction, initial episode of care \\
410.80 & Acute myocardial infarction of other specified sites, episode of care unspecified \\
410.81 & Acute myocardial infarction of other specified sites, initial episode of care \\
410.90 & Acute myocardial infarction of unspecified site, episode of care unspecified \\
410.91 & Acute myocardial infarction of unspecified site, initial episode of care \\
\hline
\end{tabular}

observation for the total (AMI-free) population at the start of each time interval. Although incidence rates are preferred over incidence proportions when there is longterm follow up (i.e., $>30$ days), nearly all the literature identified in this area presented information in the form of incidence proportions; thus, only IPs are presented in the Results in order to facilitate better comparisons with the literature. However, incidence rate information is contained in the Additional file 1.

\section{Results}

A total of 67,533 SF patients, 87,572 THA patients, and 167,480 TKA patients were eligible for the study. The median age at the index date was 59, 65, and 66 years for SF, THA, and TKA patients, respectively; there were more white patients (>88.00\%) across all surgical types, slightly more females undergoing THA (53.23\%) and TKA (59.73\%), and slightly more males undergoing SF (56.95\%). Some of the most prevalent medical conditions included type 2 diabetes (13.91\% for SF, $12.17 \%$ for THA, and $16.22 \%$ for TKA), cardiac dysrhythmias $(9.12 \%$ for SF, $12.45 \%$ for THA, and $13.09 \%$ for TKA), chronic ischemic disease $(8.86 \%$ for SF, $8.91 \%$ for THA, and $9.36 \%$ for TKA), hypothyroidism (7.06\% for SF, 9.56\% for THA, and $10.80 \%$ for TKA), and anemia (7.14\% for SF, $15.14 \%$ for THA, and $12.84 \%$ for TKA). Within all three surgical cohorts, a history of AMI was rare (i.e., between 0.52 and $0.62 \%$ across cohorts). Dementia, deep vein thrombosis, and pulmonary embolism were also rare among all three surgical cohorts. The average length of hospital stay (LHS) (for the index hospitalization) was 3.41, 2.69, and 2.89 days for SF, THA, and TKA, respectively. Lastly, although less than $1.00 \%$ of SFs were revisional, $39.88 \%$ of THAs and $37.66 \%$ of TKAs were revisional surgeries. Table 3 shows the baseline demographics and clinical/ surgical characteristics of the elective SF, THA, and TKA patient population.

The IP of AMI following elective SF was 0.36\% (95\% CI: $0.31 \%, 0.41 \%$ ) during initial hospitalization, $0.48 \%(95 \%$ CI: $0.43 \%, 0.54 \%) \leq 30$ days, $0.62 \%$ $(95 \%$ CI: $0.56 \%, \quad 0.68 \%) \leq 90$ days, $0.79 \% \quad(95 \%$ CI: $0.72 \%, 0.86 \%) \leq 180$ days, and $1.05 \%$ (95\% CI: $0.97 \%$, $1.12 \%) \leq 365$ days post-operation. The IP of AMI following elective THA was $0.28 \%$ (95\% CI: $0.24 \%, 0.31 \%$ ) during initial hospitalization, $0.37 \%$ (95\% CI: $0.33 \%$, $0.41 \%) \leq 30$ days, $0.50 \%$ ( $95 \%$ CI: $0.45 \%, 0.55 \%) \leq 90$ days, $0.65 \%(95 \%$ CI: $0.60 \%, 0.70 \%) \leq 180$ days, and $0.93 \%$ (95\% CI: $0.87 \%, \quad 0.99 \%) \leq 365$ days post-operation. The IP of AMI following elective TKA was $0.25 \%$ (95\% CI: $0.22 \%, 0.27 \%$ ) during initial hospitalization, $0.34 \%(95 \% \mathrm{CI}: 0.31 \%, 0.36 \%) \leq 30$ days, $0.43 \%$ $(95 \%$ CI: $\quad 0.40 \%, \quad 0.46 \%) \leq 90$ days, $0.56 \% \quad(95 \%$ CI: $0.53 \%, 0.60 \%) \leq 180$ days, and $0.85 \%$ (95\% CI: $0.80 \%$, $0.89 \%) \leq 365$ days post-operation. Tables 4,5 , and 6 show 
Table 3 Baseline demographics, clinical characteristics, and surgical characteristics of the elective spinal fusion, total hip arthroplasty, and total knee arthroplasty cohorts

\begin{tabular}{|c|c|c|c|c|c|c|}
\hline \multirow[t]{2}{*}{ Characteristic, N (\%) except where specified } & \multicolumn{2}{|l|}{ Spinal fusion } & \multicolumn{2}{|l|}{ Total hip replacement } & \multicolumn{2}{|c|}{ Total knee replacement } \\
\hline & Number of patients & $\%$ & Number of patients & $\%$ & Number of patients & $\%$ \\
\hline Total & 67,533 & & 87,572 & & 167,480 & \\
\hline \multicolumn{7}{|l|}{ Demographic characteristics } \\
\hline \multicolumn{7}{|l|}{ Age at index date } \\
\hline Mean (SD) & $58.27(13.37)$ & & $64.45(11.00)$ & & $65.79(9.48)$ & \\
\hline Median (Min, Max) & $59(18,85)$ & & $66(18,85)$ & & $66(18,85)$ & \\
\hline$\geq 18-55$ & 26,790 & 39.67 & 17,639 & 20.14 & 23,876 & 14.26 \\
\hline $56-65$ & 18,559 & 27.48 & 28,302 & 32.32 & 56,810 & 33.92 \\
\hline $66-75$ & 16,114 & 23.86 & 26,419 & 30.17 & 58,340 & 34.83 \\
\hline $76-<86$ & 6,070 & 8.99 & 15,212 & 17.37 & 28,454 & 16.99 \\
\hline \multicolumn{7}{|l|}{ Sex } \\
\hline Male & 38,457 & 56.95 & 40,938 & 46.75 & 67,397 & 40.24 \\
\hline Female & 29,053 & 43.02 & 46,611 & 53.23 & 100,028 & 59.73 \\
\hline Unknown & 23 & 0.03 & 23 & 0.03 & 55 & 0.03 \\
\hline \multicolumn{7}{|l|}{ Race } \\
\hline White & 59,936 & 88.75 & 78,802 & 89.99 & 148,096 & 88.43 \\
\hline Black or African American & 4,417 & 6.54 & 5,757 & 6.57 & 11,466 & 6.85 \\
\hline Asian & 372 & 0.55 & 228 & 0.26 & 1,110 & 0.66 \\
\hline Other/Unknown & 2,808 & 4.16 & 2,785 & 3.18 & 6,808 & 4.06 \\
\hline \multicolumn{7}{|l|}{ Clinical characteristics in 183 -day baseline } \\
\hline Acute myocardial infarction & 418 & 0.62 & 490 & 0.56 & 869 & 0.52 \\
\hline Anemia & 4,819 & 7.14 & 13,262 & 15.14 & 21,504 & 12.84 \\
\hline Angina & 3,533 & 5.23 & 3,533 & 4.03 & 8,063 & 4.81 \\
\hline Asthma/wheezing/bronchospasm & 5,284 & 7.82 & 6,382 & 7.29 & 13,425 & 8.02 \\
\hline Bronchitis/chronic obstructive pulmonary disease & 3,849 & 5.70 & 4,722 & 5.39 & 8,212 & 4.90 \\
\hline Cardiac dysrhythmias & 6,157 & 9.12 & 10,900 & 12.45 & 21,923 & 13.09 \\
\hline Chronic ischemic disease & 5,984 & 8.86 & 7,807 & 8.91 & 15,669 & 9.36 \\
\hline Deep vein thrombosis & 592 & 0.88 & 949 & 1.08 & 2,080 & 1.24 \\
\hline Dementia & 218 & 0.32 & 380 & 0.43 & 516 & 0.31 \\
\hline Diabetes, type 1 & 480 & 0.71 & 331 & 0.38 & 774 & 0.46 \\
\hline Diabetes, type 2 & 9,392 & 13.91 & 10,659 & 12.17 & 27,164 & 16.22 \\
\hline Heart failure & 1,458 & 2.16 & 2,400 & 2.74 & 4,657 & 2.78 \\
\hline Hyperthyroidism & 191 & 0.28 & 381 & 0.44 & 731 & 0.44 \\
\hline Hypothyroidism & 4,765 & 7.06 & 8,375 & 9.56 & 18,094 & 10.80 \\
\hline Intracranial hemorrhage & 139 & 0.21 & 83 & 0.09 & 140 & 0.08 \\
\hline $\begin{array}{l}\text { Liver disease and cirrhosis (excluding hepatitis, } \\
\text { alcoholic liver disease) }\end{array}$ & 1,023 & 1.51 & 1,206 & 1.38 & 2,347 & 1.40 \\
\hline Liver failure & 50 & 0.07 & 67 & 0.08 & 111 & 0.07 \\
\hline Malignant neoplasms & 0 & 0.00 & 0 & 0.00 & 0 & 0.00 \\
\hline Multiple sclerosis & 186 & 0.28 & 172 & 0.20 & 282 & 0.17 \\
\hline Peripheral vascular disease & 2,626 & 3.89 & 3,007 & 3.43 & 5,306 & 3.17 \\
\hline Psoriatic arthroplasty & 72 & 0.11 & 87 & 0.10 & 197 & 0.12 \\
\hline Pulmonary embolism & 247 & 0.37 & 402 & 0.46 & 1,015 & 0.61 \\
\hline Reactive arthritis & 830 & 1.23 & 253 & 0.29 & 154 & 0.09 \\
\hline Renal failure & 2,442 & 3.62 & 4,229 & 4.83 & 8,157 & 4.87 \\
\hline Respiratory failure & 922 & 1.37 & 862 & 0.98 & 1,712 & 1.02 \\
\hline Spondyloarthritis, including ankylosing spondylitis & 2,031 & 3.01 & 771 & 0.88 & 554 & 0.33 \\
\hline Stroke & 529 & 0.78 & 580 & 0.66 & 1,094 & 0.65 \\
\hline
\end{tabular}


Table 3 (continued)

\begin{tabular}{|c|c|c|c|c|c|c|}
\hline \multirow[t]{2}{*}{ Characteristic, N (\%) except where specified } & \multicolumn{2}{|l|}{ Spinal fusion } & \multicolumn{2}{|l|}{ Total hip replacement } & \multicolumn{2}{|c|}{ Total knee replacement } \\
\hline & Number of patients & $\%$ & Number of patients & $\%$ & Number of patients & $\%$ \\
\hline \multicolumn{7}{|l|}{ Surgical characteristics for index surgery } \\
\hline Allogenic blood transfusion during surgery & 16 & 0.02 & 32 & 0.04 & 22 & 0.01 \\
\hline Existing permanently implanted device or prosthesis & 1,839 & 2.72 & 2,149 & 2.45 & 3,470 & 2.07 \\
\hline Revisional surgery & 538 & 0.80 & 34,924 & 39.88 & 63,065 & 37.66 \\
\hline \multicolumn{7}{|l|}{ Total length of hospital stay } \\
\hline Mean (SD) & $3.41(3.93)$ & & $2.69(2.42)$ & & $2.89(2.21)$ & \\
\hline Median (Min, Max) & $3(1,90)$ & & $2(1,90)$ & & $3(1,90)$ & \\
\hline Use of implanted material during surgery & 3,840 & 5.69 & 1,401 & 1.60 & 1,784 & 1.07 \\
\hline
\end{tabular}

the IP information for AMI among patients undergoing elective SF, THA, and TKA, respectively.

Stratified analyses revealed that the IP of AMI was higher among patients who were older, male, had a history of AMI, and had a history of diabetes across the three types of surgery at each risk window. For example, the IP of post-operative AMI among elective SF patients during index hospitalization was $0.10 \%$ (95\% CI: $0.06 \%$, $0.14 \%$ ) among those aged $\geq 18$ to 55 years, $0.31 \%$ (95\% CI: $0.23 \%, 0.40 \%$ ) among those aged 56 to 65 years, $0.60 \%$ (95\% CI: $0.48 \%, 0.72 \%$ ) among those aged 66 to 75 years, and $1.01 \%$ (95\% CI: $0.76 \%, 1.26 \%)$ among those aged 76 to $<86$ years. Moreover, the IP of post-operative AMI among elective THA patients $\leq 365$ days post-operation was $1.16 \%(95 \%$ CI: $1.06 \%, 1.27 \%)$ for men and $0.72 \%$ (95\% CI: $0.65 \%, 0.80 \%$ ) for women. Additionally, the IP of AMI was higher among patients who had greater LHS across the three types of surgery at each risk window; however, it should be noted that these longer hospital stays could be a result of AMI instead of a reverse relationship (i.e., where AMI is the consequence of a longer hospital stay).

The IP of AMI was slightly higher among black patients for TKA in most risk windows and for SF up to 90 days post-operation compared to white patients, while the IP of AMI was higher among white patients for THA at each risk window. For instance, the IP of post-operative AMI among elective TKA patients $\leq 30$ days post-operation was $0.37 \%$ ( $95 \%$ CI: $0.26 \%, 0.48 \%$ ) for black patients and $0.33 \%$ (95\% CI: $0.30 \%, 0.36 \%$ ) for white patients. Generally, SF patients with same day revisional surgery had higher IPs of AMI across risk windows compared to patients who did not have same day revisional surgery; however, the opposite association was observed for THA and TKA patients (i.e., the IP of AMI was lower for those with same day revisional surgery compared to those who did not have same day revisional surgery across risk windows).
Detailed incidence rate information can be found in the Additional file 1 (i.e., Table S1, Table S2, and Table S3). The incidence rate of AMI per 1000 personyears (PYs) following elective SF was 18.12 (95\% CI: $16.64,19.73) \leq 180$ days post-operation and $12.82(95 \%$ CI: $11.90,13.80) \leq 365$ days post-operation. The incidence rate of AMI per 1000 PYs following elective THA 15.03 (95\% CI: 13.83, 16.32) $\leq 180$ days post-operation and $11.45(95 \% \mathrm{CI}: 10.69,12.27) \leq 365$ days post-operation. The incidence rate of AMI per 1000 PYs following elective TKA was 12.77 (95\% CI: 11.97, 13.61) $\leq 180$ days post-operation and 10.17 (95\% CI: 9.66, 10.72) $\leq 365$ days post-operation. It should be highlighted that the incidence rate of AMI following elective surgery decreased consistently from index hospitalization to $\leq 365$ days post-operation across all three surgical cohorts.

\section{Discussion}

\section{Summary}

This study identified 67,533 SF patients, 87,572 THA patients, and 167,480 TKA patients who underwent elective surgeries within the Optum EHR database. The IP of AMI following these elective procedures was generally highest among the SF cohort compared to the THA and TKA cohorts. When stratified by relevant demographic and clinical characteristics, we found that the IP of postoperative AMI was higher among patients who were older, male, with longer hospital stays, had a history of AMI, and had a history of diabetes.

\section{Spinal fusion cohort}

Adogwa et al. performed a retrospective database study using the American College of Surgeons (ACS) National Surgical Quality Improvement Program (NSQIP) database from January 2008 through December 2014 and analyzed 23,102 patients undergoing lumbar decompression and fusion procedures; the authors found that patients with extended LHS had a higher incidence of 


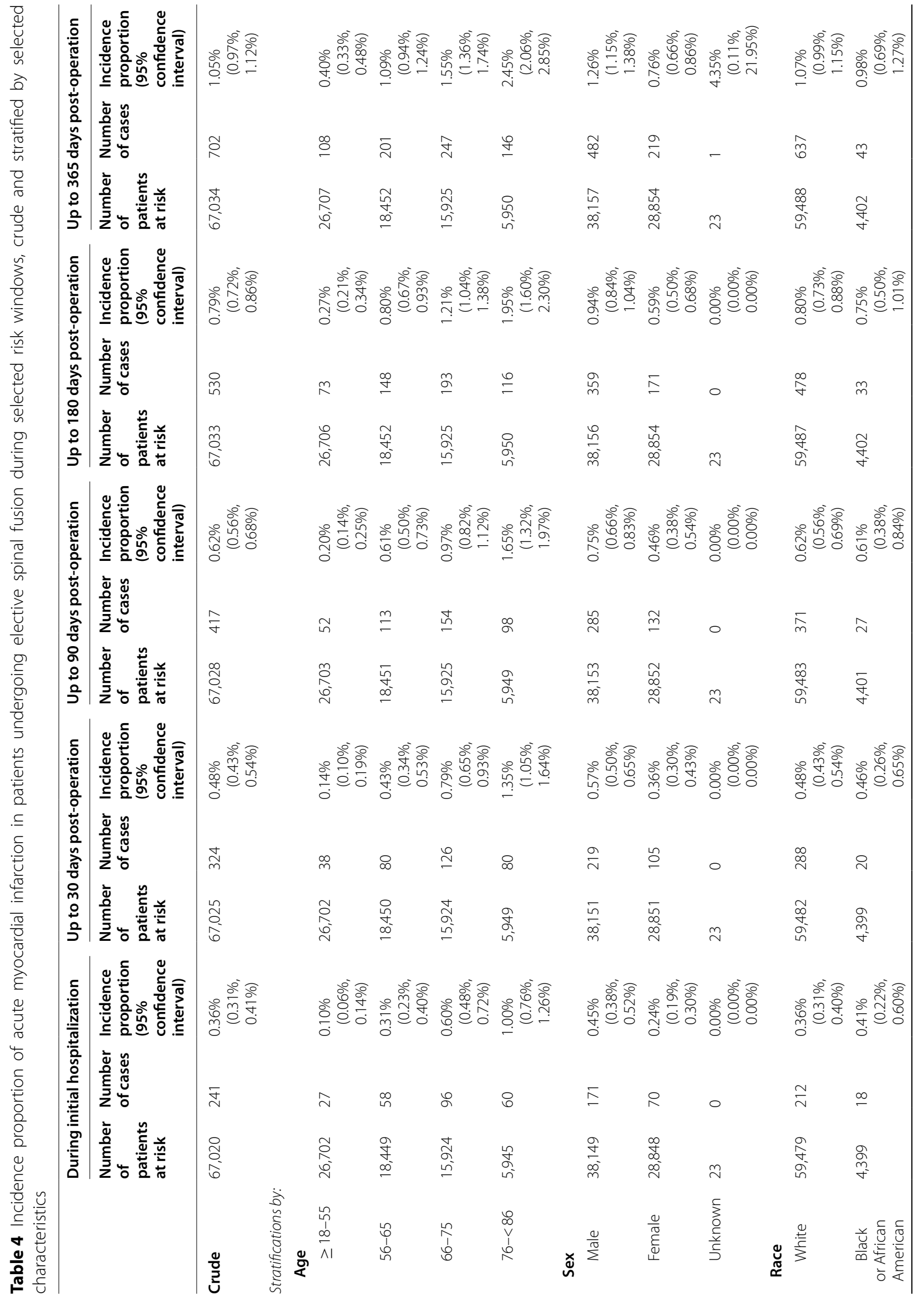




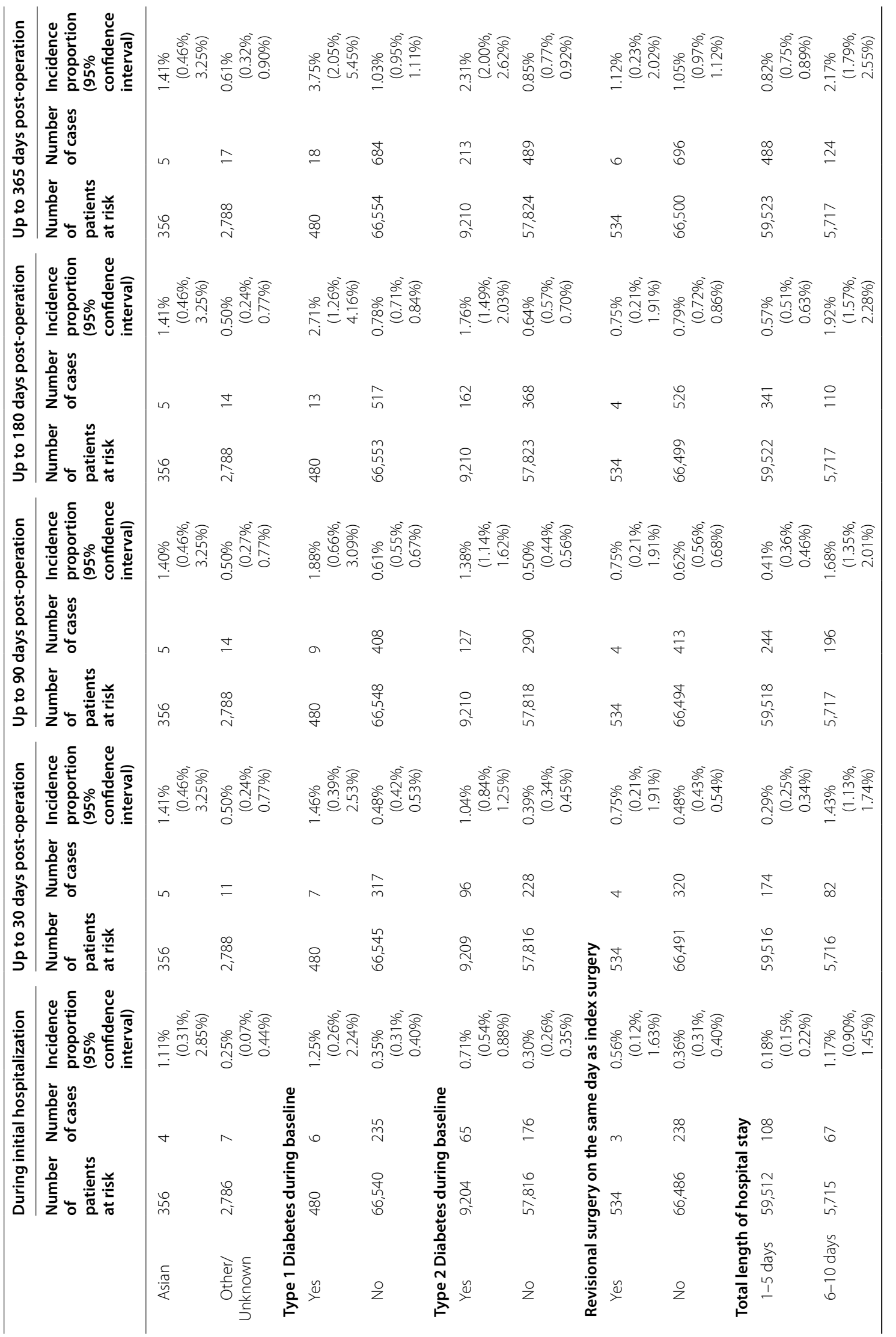




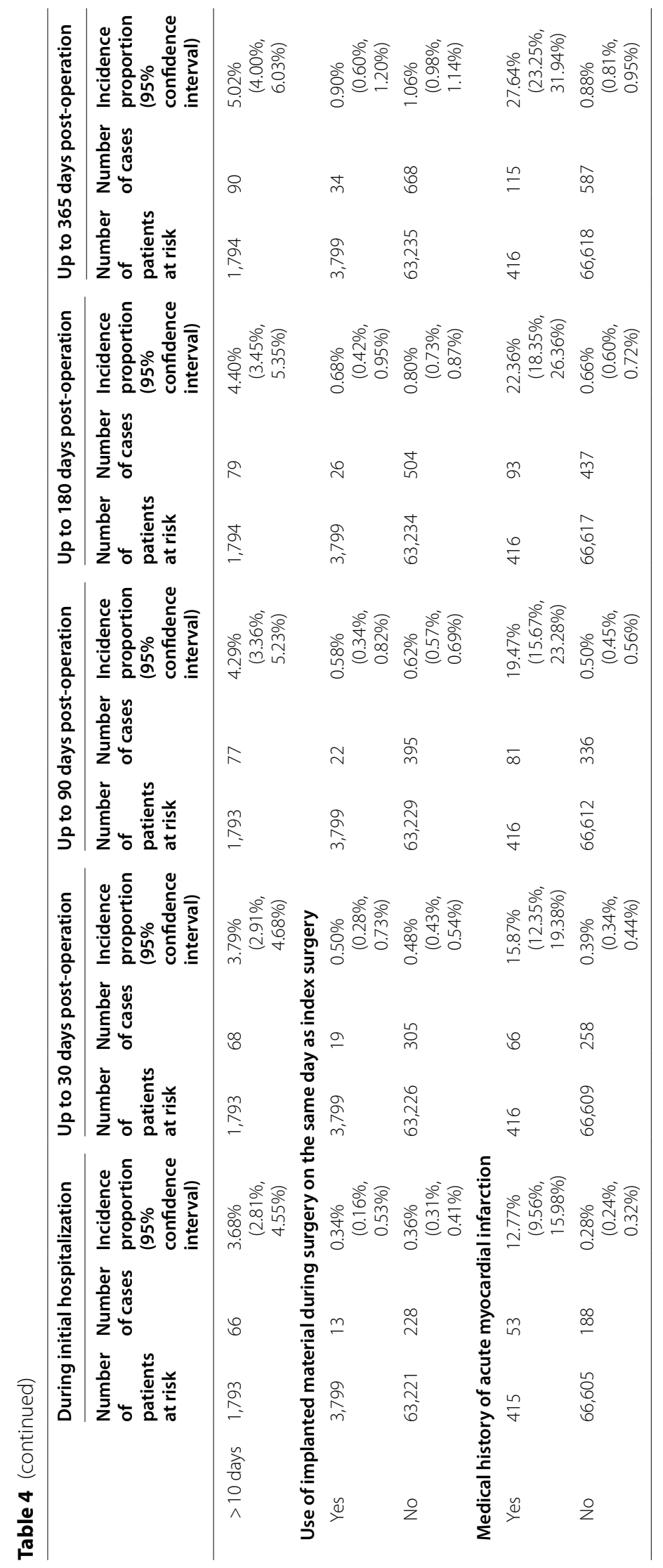




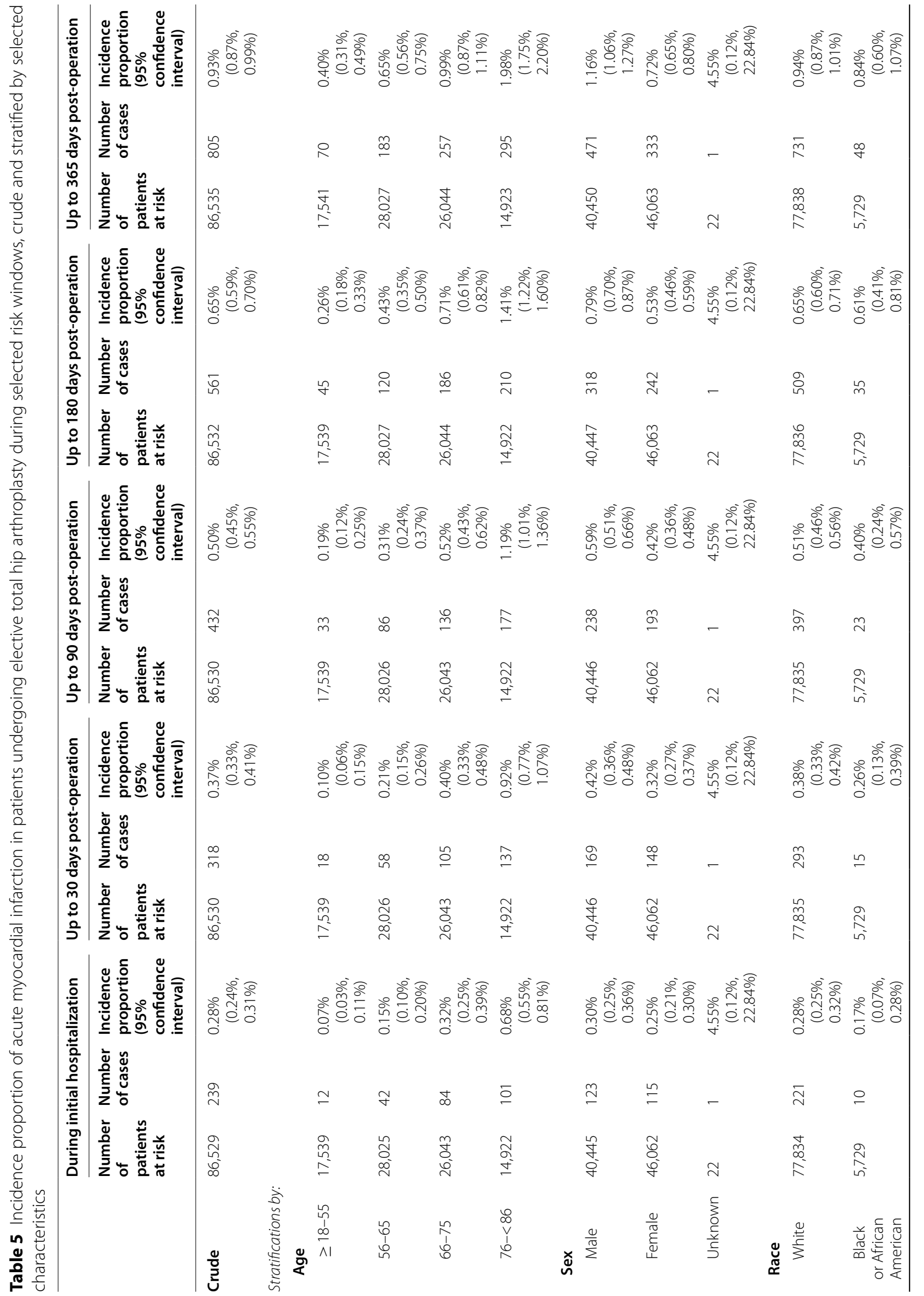




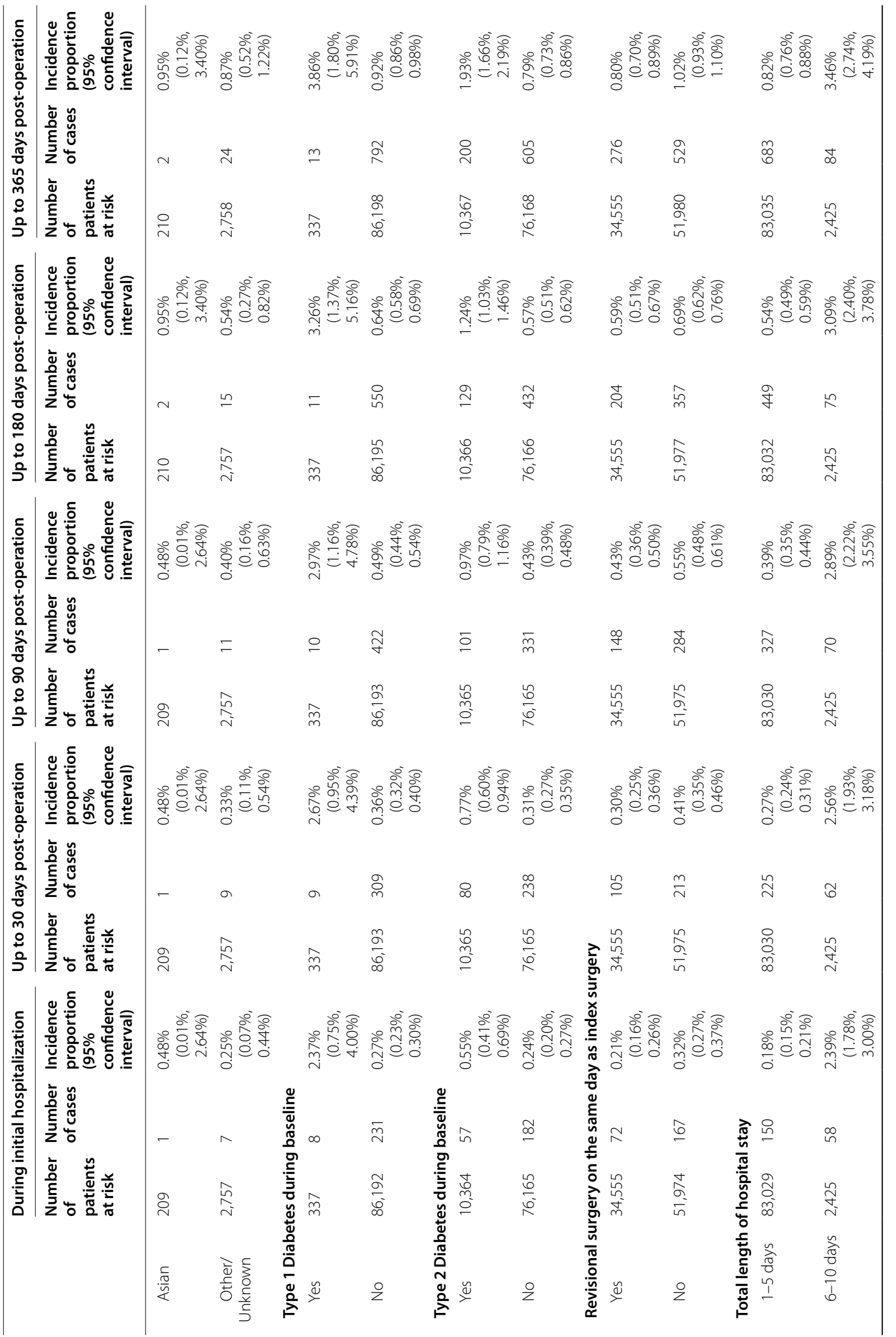




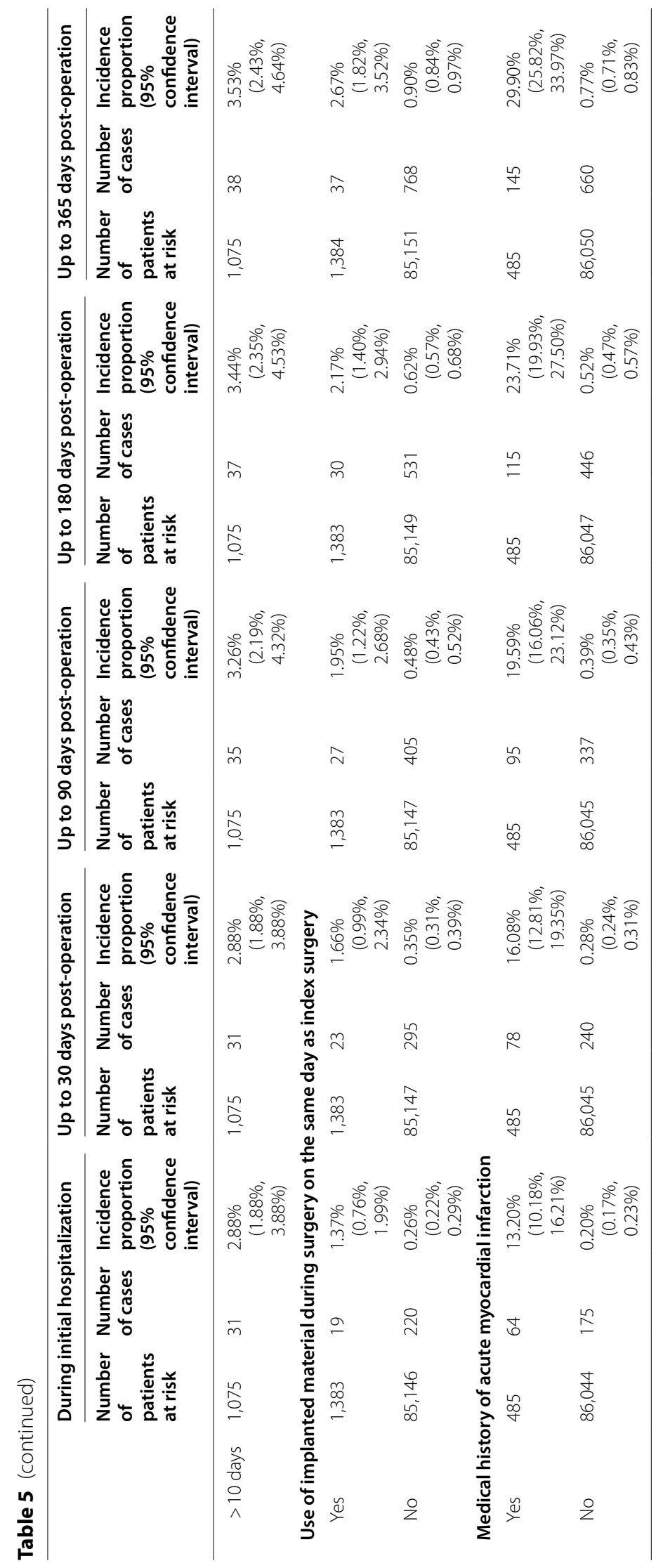




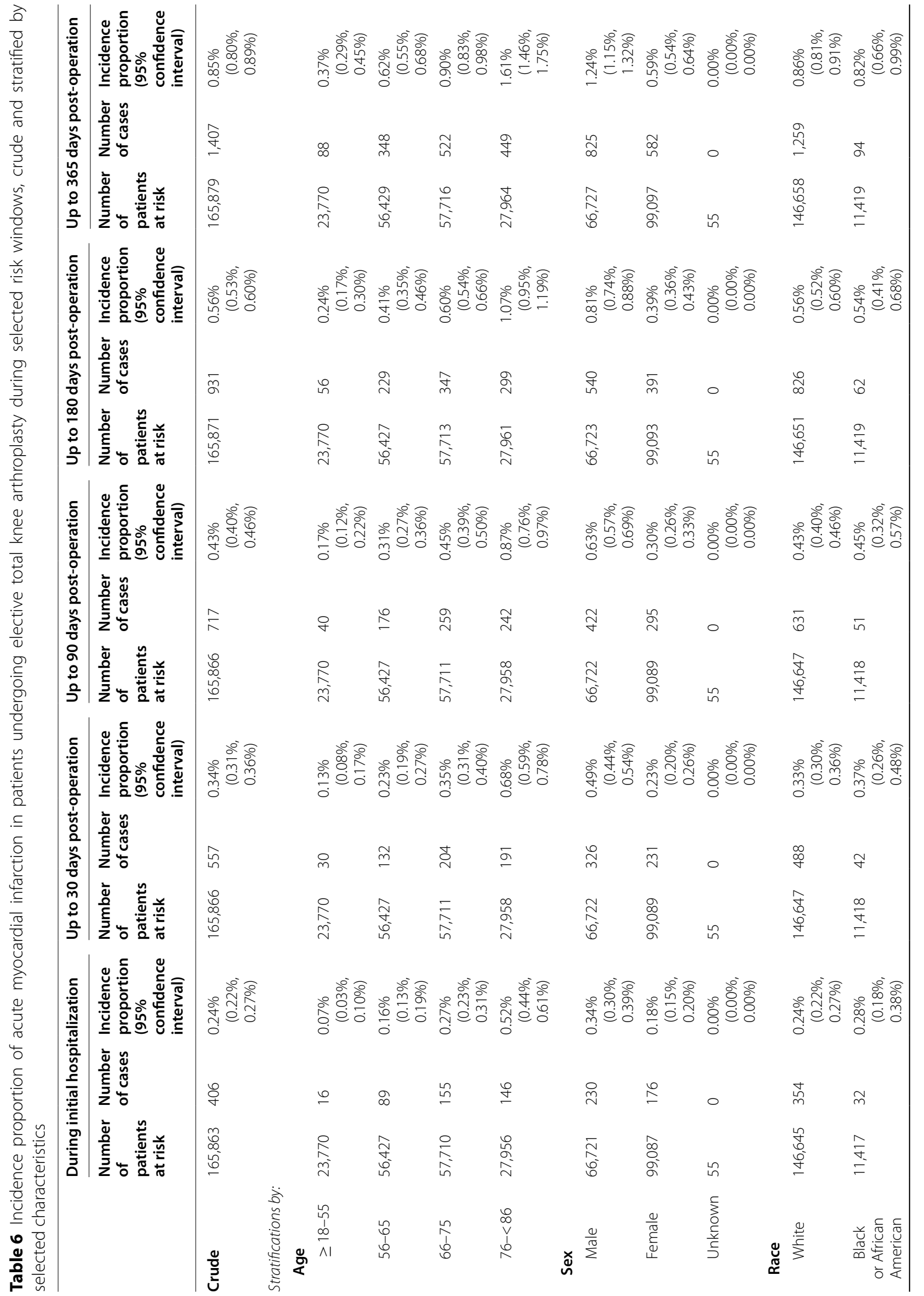




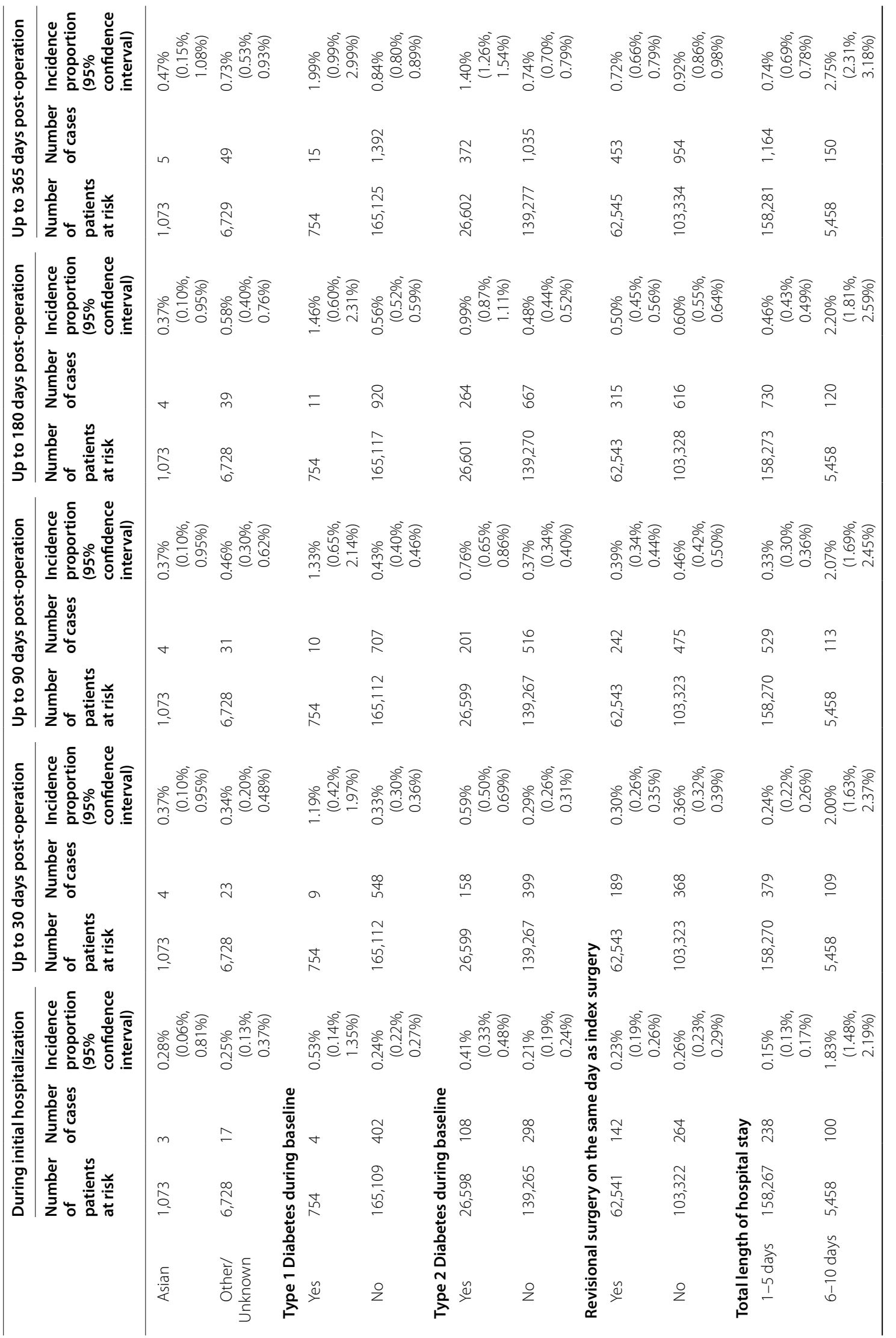




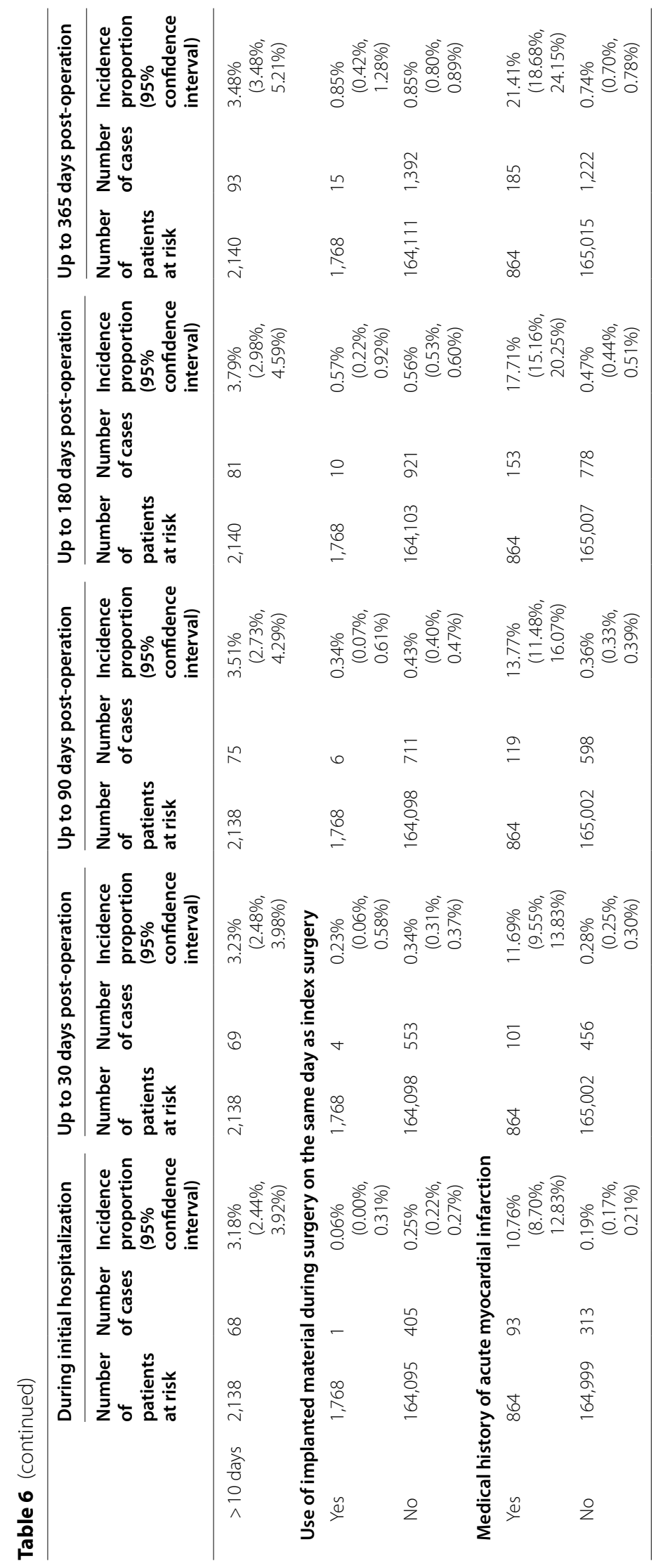


post-operative MI: $0.16 \%$ for those with normal LHS and $1.29 \%$ for those with extended LHS [11]. Similarly, another investigation by Adogwa et al. of adult patients aged 65 and older in the ACS NSQIP database who underwent certain SF procedures $(n=4730)$ from 2008 through 2014 also found that patients with extended LHS had a higher incidence of post-operative MI: $0.06 \%$ for those with normal LHS and $1.18 \%$ for those with extended LHS [12]. In both studies, the authors stressed that much of the variation in LHS after spinal surgery was most likely due to differences in practice style or surgeon preference (as opposed to in-hospital complications or baseline comorbidities). In the same vein, Shen et al. conducted a retrospective cohort analysis of 254,640 patients undergoing elective SF in the Nationwide Inpatient Sample (NIS) from 2001 to 2005 and found that the IP of cardiovascular complications during hospitalization increased with age: $0.52 \%$ for those aged 20 to 24 years, $0.52 \%$ for those aged 35 to 49 years, $1.06 \%$ for those aged 50 to 64 years, $2.32 \%$ for those aged 64 to 74 years, and $3.20 \%$ for those aged 75 years or more [13]; although we used different age categorizations, we too found a similar relationship between age and the incidence of post-operative AMI.

Moreover, Chung et al. performed a retrospective cohort study of 15,618 patients undergoing elective SF in the ACS NSQIP between 2006 and 2013 and concluded that patients with metabolic syndrome had increased incidence of post-operative MI (0.5\%) compared to those without metabolic syndrome (0.3\%) [6]. Likewise, Memstoudis et al. also investigated the relation between postoperative MI and metabolic syndrome, but these authors used the NIS database from 1998 to 2008 and patients undergoing primary posterior lumbar fusion; nonetheless, Metmstoudis et al. also found that patients with metabolic syndrome had increased incidence of postoperative MI (0.6\%) compared to those without metabolic syndrome (0.3\%) [14]. Although we did not look at this condition explicitly, metabolic syndrome is a composite condition that includes diabetes; we found that patients with type 2 diabetes had increased incidence of post-operative AMI compared to those without type 2 diabetes, so our finding is in line with the Chung et al. and Memstoudis et al. studies. Lastly, Basques et al. performed a retrospective cohort study of the ACS NSQIP database from 2005 to 2013 and examined post-operative MI among patients that underwent primary and revisional posterior lumbar fusion; the authors found the 30-day incidence of MI was similar among patients who underwent primary posterior lumbar fusion (0.3\%) compared to patients who underwent revision posterior lumbar fusion $(0.2 \%)$ [15]. This finding somewhat aligns with the association that we found: the 30-day incidence of AMI was $0.75 \%$ among patients who underwent revisional SF and $0.48 \%$ among patients who did not undergo revisional SF. However, less than 600 patients underwent revisional SF in our cohort; therefore, the IP estimate may not be stable.

Total hip arthroplasty and total knee arthroplasty cohorts Kreder et al. evaluated 26,320 patients who underwent primary THA and TKA by performing a retrospective cohort study of administrative data in Ontario, Canada; the authors reported that the incidence of AMI increased with age among both THA patients $(0.47 \%$ for those aged 65 to 79 years and $1.28 \%$ for those aged 80 years or greater) and TKA patients $(0.45 \%$ for those aged 65 to 79 years and $1.09 \%$ for those aged 80 years or greater) [16]. Likewise, Koenig et al. performed a retrospective review of 306 patients who underwent revision THA; the authors found that the 90-day incidence of post-operative MI was $0.0 \%$ for those aged less than 65 years and $1.6 \%$ for those aged 65 to 79 years [17]. As was the case with SF cohort, we also found that the incidence of post-operative AMI increased with age in both the THA and TKA cohorts.

Moreover, Blum et al. conducted a retrospective cohort study of 17,385 patients that underwent primary TKA within the Pennsylvania Health Care Cost Containment Council data from 2001 to 2007; the authors found the 30 -day incidence of post-operative MI was $0.5 \%$ for white patients and $0.2 \%$ for black patients [7]; their finding runs slightly counter to our own as we found that 30-day IP of post-operative AMI was $0.33 \%$ for white patients and $0.37 \%$ for black patients. However, it should be noted that these authors used only one ICD-9 code to define TKA (81.54), and that their analysis focused on one state as opposed to the entire US (which was the case in our study); nonetheless, we used virtually the same MI definitions [7]. With regards to sex-specific differences, Basques et al. performed a retrospective cohort study of elective THA and TKA patients using the NIS from 2002 to 2011 and concluded that the odds of MI among males were 1.6 times the odds among females [18]; we found a similar relationship in that the men in our study generally had higher incidences of AMI compared to women across all risk windows for both THA and TKA.

Furthermore, Pulido et al. performed an institutional review of their prospective database of patients undergoing elective joint arthroplasty and identified 15,383 patients who had THA or TKA; the authors found that the incidence of in-hospital MI was higher among revisional surgery than among primary surgery patients for both THA $(0.35$ vs. $0.16 \%)$ and TKA $(0.62$ and $0.33 \%$ ) [19]. We found an opposite association for both TKA $(0.23 \%$ for revisional surgery and $0.26 \%$ for 
non-revisional surgery) and THA (0.21\% for revisional surgery and $0.32 \%$ for non-revisional surgery) during index hospitalization. However, it should be noted that their analysis comprised of one institution (as opposed to our hospital network-based analysis). Still, Khatod et al. performed a retrospective review of 17,080 primary and revisional TKAs at Southern California Kaiser Permanente between 1995 and 2004 and found that the postoperative incidences of MI were approximately the same for revisional and primary TKA [20], which is roughly in accordance with what was found for our TKA population. Nonetheless, Mohamed et al. conducted a retrospective cohort study of Medicare claims data in the year 2000 to identify patients undergoing primary and revision TKA and determined that the 90-day incidence of post-operative MI was $0.8 \%$ for primary TKA and $1.0 \%$ for revisional TKA [21]. We again see that our 90-day incidence finding $(0.39 \%$ for revisional TKA compared to $0.43 \%$ for primary TKA) is not in line with the literature. Although Mohamed et al. also used a national database, they used both ICD-9 and Current Procedural Terminology (CPT) codes to identify TKA and only looked at data for the year 2000 (as opposed to the eleven-year period analyzed here) [21].

\section{Recurrent AMI}

Although no studies looked at the incidence of postoperative AMI among patients with a history of AMI, it is well-established that patients who survive an AMI episode have an increased risk of a future AMI [22]. Thus, our analysis (among those with a history of AMI) agree with such a relationship as we found that patients with a history of AMI had a drastically higher incidence than those without such a history; for example, the IP of postoperative AMI during index hospitalization among the TKA cohort was $10.76 \%$ for those with a medical history of AMI compared to $0.19 \%$ for those without such a history.

\section{Database considerations}

It is noteworthy that our study used Optum EHR database while most studies in the literature used NSQIP or NIS. Because of differences in these data sources, it may not be surprising that our results would not exactly align with the incidence information found in the literature. For instance, a 2016 study evaluated the variability in standard outcomes of posterior lumbar fusion between the University HealthSystem Consortium (UHC) and the NIS and found that the databases had similar patient populations undergoing posterior lumbar fusion, but that the UHC database reported significantly higher MI rates as well as longer lengths of hospital stay [23]. Another study by Jain et al. compared similar patient populations between a multicenter, surgeon-maintained database (SMD) and a Centers for Medicare \& Medicaid Services claims database (MCD); the authors ultimately found that the incidence of post-operative AMI was slightly higher in the SMD (2.0\%) than in the MCD (1.8\%) [24].

Additionally, recent studies have also shown that certain variables have changed over time within both NIS and NSQIP [25-28]; thus, even comparisons within the same database can be fraught. For example, Shultz et al. reported that the 30-day incidence of post-operative MI among patients who underwent elective posterior lumbar fusion surgery with or without interbody fusion in the ACS NSQIP database changed from $0.25 \%$ over the period of 2005 to 2010 to $0.31 \%$ over the period of 2011 to 2014 [26]. Moreover, Wolf et al. conducted a retrospective review of Medicare beneficiaries who underwent primary or revisional THA between 1991 and 2008 and reported that the 90-day incidence of post-operative MI changed from $0.4 \%$ over the period of 1991 to 1993 to $0.7 \%$ over the period of 2006 to 2008; the authors speculated that this elevation was likely due to an increase in medical comorbidities among patients as well as an increase in surgical complexity [29].

\section{Strengths and limitations}

The Optum EHR database has both inpatient and outpatient data as well as a large sample size that enabled us to generate real-world incidence estimates that are generalizable to a segment of the commercially insured US population (i.e., those in the Optum network). However, our patient population was selected to be relatively healthy, so this selection may affect the overall generalizability.

Nonetheless, this study provides additional information about AMI in a variety of risk windows. Most studies identified in the literature analyzed AMI events during index hospitalization or in the 30- or 90-day risk windows. Our study thus builds on previous work by not only estimating AMI incidences during index hospitalization and the 30- and 90-day risk windows but also by generating data on AMI incidence in the 180- and 365day risk windows; it is important to have data in these longer risk windows to ensure no incident AMI events are missed (even though it is more likely for AMI to occur in the shorter risk windows). Lastly, our study adds to the existing literature about AMI incidence by presenting such information in the form of incidence rates; most of the AMI incidence information in the literature is presented in the form of IPs (which can be more biased due to censoring for longer follow-up periods), and thus there is a paucity of data in the form of incidence rates.

Still, it must be noted that EHR data were originally developed to improve patient care/modernize billing procedures and thus were not designed as research 
resources. As a result, EHR data tend to have more missing data (when compared to data obtained from clinical trials and/or prospective studies with primary data collection), and this missingness can potentially bias results [30]. However, given that elective surgery and AMI events generally require medical encounters, they would have been recorded in Optum EHR; therefore, the likelihood of missing information for these key variables would be very low. Like other studies utilizing secondary data sources without validation (e.g., medical chart review), exposure and outcome misclassification are possible. Furthermore, patients may have sought healthcare outside Optum EHR prior to the index surgery, so it is possible that a patient developed an AMI prior to the index surgery; similarly, some incident events may have been missed if a patient sought care outside the system after surgery.

Lastly, this study employed a descriptive analysis approach; thus, comparisons within stratified analyses may be subject to confounding factors that were not properly controlled. As a result, these comparisons must be interpreted with caution. Future studies in this area should consider multiple regression modeling and/or multivariable stratification techniques to better account for potential confounding. Future researchers should also consider the impact of effect measure modification on their results.

\section{Conclusion}

This study estimated the incidence of AMI using an EHR database among adults undergoing elective SF, THA, and TKA during various post-operative risk windows and among different sub-groups. The IP of AMI following these elective procedures was generally highest among the SF cohort compared to the THA and TKA cohorts. When stratified by relevant demographic and clinical characteristics, we found that the IP of post-operative AMI was higher among patients who were older, male, with longer hospital stays, had a history of AMI, and had a history of diabetes. Future studies are warranted to confirm these findings via improved confounder control and to identify effect measure modifiers.

\section{Supplementary Information}

The online version contains supplementary material available at https://doi. org/10.1186/s13037-021-00305-6.

Additional file 1: Supplemental Table 1. Incidence rate of acute myocardial infarction in patients undergoing elective spinal fusion during selected risk windows, crude and stratified by selected characteristics. Supplemental Table $\mathbf{2}$. Incidence rate of acute myocardial infarction in patients undergoing elective total hip arthroplasty during selected risk windows, crude and stratified by selected characteristics. Supplemental
Table 3. Incidence rate of acute myocardial infarction in patients undergoing elective total knee arthroplasty during selected risk windows, crude and stratified by selected characteristics.

Acknowledgements

Not applicable.

Authors' contributions

PJA, JM, and KH contributed to the study design. PJA, KH, XZ, QL, RG, CS, and SM contributed to data analyses. PJA and KH drafted the manuscript with input from JM, XZ, QL, RG, CS, and SM. All authors read and approved the final manuscript.

Funding

This work was funded by Pfizer Inc.

\section{Availability of data and materials}

The data that support the findings of this study are available from Optum but restrictions apply to the availability of these data and so are not publicly available. Data are however available from the authors upon reasonable request and with permission of Optum.

\section{Declarations}

Ethics approval and consent to participate

As this study involved anonymized structured data, which according to applicable legal requirements do not contain data subject to privacy laws, obtaining informed consent from patients was not required.

\section{Consent for publication}

Not applicable.

Competing interests

All authors are employees of Pfizer Inc., New York, NY, USA.

\section{Author details}

${ }^{1}$ Global Medical Epidemiology \& Big Data Analysis, Pfizer Inc., 235 E 42nd St, New York, NY 10017, USA. Safety Surveillance Research, Pfizer Inc., New York, NY, USA. ${ }^{3}$ Global Medical Epidemiology \& Big Data Analysis, Pfizer Inc., Collegeville, PA, USA. ${ }^{4}$ Real World Evidence Center of Excellence, Pfizer Inc., New York, NY, USA.

Received: 9 June 2021 Accepted: 3 August 2021

Published online: 18 September 2021

\section{References}

1. Roth GA, Johnson C, Abajobir A, et al. Global, regional, and national burden of cardiovascular diseases for 10 causes, 1990 to 2015. J Am Coll Cardiol. 2017;70(1):1-25. https://doi.org/10.1016/j.jacc.2017.04.052.

2. Benjamin EJ, Muntner P, Alonso A, et al. Heart disease and stroke statistics-2019 update: a report from the American Heart Association [published correction appears in Circulation. 2020 Jan 14;141(2):e33]. Circulation. 2019;139(10):e56-528. https://doi.org/10.1161/CIR.00000 00000000659.

3. Roger VL. Epidemiology of myocardial infarction. Med Clin North Am. 2007;91(4):537-ix. https://doi.org/10.1016/j.mcna.2007.03.007.

4. Boateng S, Sanborn T. Acute myocardial infarction. Dis Mon. 2013;59(3):83-96. https://doi.org/10.1016/j.disamonth.2012.12.004.

5. Lee TL, Kao FC, Hsu YC, Lo YY, Tu YK. Perioperative acute myocardial infarction rate in chronic renal disease patients undergoing orthopedic surgery: Is there any difference between dialyzed and nondialyzed patients? PLoS One. 2019;14(1):e0210554. https://doi.org/10.1371/journal. pone.0210554.

6. Chung AS, Campbell D, Waldrop R, Crandall D. Metabolic syndrome and 30-day outcomes in elective lumbar spinal fusion. Spine (Phila Pa 1976). 2018;43(9):661-6. https://doi.org/10.1097/BRS.0000000000002397. 
7. Blum MA, Singh JA, Lee GC, Richardson D, Chen W, Ibrahim SA. Patient race and surgical outcomes after total knee arthroplasty: an analysis of a large regional database. Arthritis Care Res (Hoboken). 2013;65(3):414-20. https://doi.org/10.1002/acr.21834.

8. Rajaee SS, Bae HW, Kanim LE, Delamarter RB. Spinal fusion in the United States: analysis of trends from 1998 to 2008. Spine (Phila Pa 1976). 2012;37(1):67-76. https://doi.org/10.1097/BRS.0b013e31820cccfb.

9. Sloan M, Premkumar A, Sheth NP. Projected volume of primary total joint arthroplasty in the U.S., 2014 to 2030. J Bone Joint Surg Am. 2018;100(17):1455-60. https://doi.org/10.2106/JBJS.17.01617.

10. Arena PJ, Mo J, Sabharwal C, et al. The incidence of stroke among selected patients undergoing elective posterior lumbar fusion: a retrospective cohort study. BMC Musculoskelet Disord. 2020;21(1):612. https:// doi.org/10.1186/s12891-020-03631-5.

11. Adogwa O, Lilly DT, Khalid S, et al. Extended length of stay after lumbar spine surgery: sick patients, postoperative complications, or practice style differences among hospitals and physicians? World Neurosurg. 2019;123:e734-9. https://doi.org/10.1016/j.wneu.2018.12.016.

12. Adogwa O, Lilly DT, Vuong VD, et al. Extended length of stay in elderly patients after anterior cervical discectomy and fusion is not attributable to baseline illness severity or postoperative complications. World Neurosurg. 2018;115:e552-7. https://doi.org/10.1016/j.wneu.2018.04.094.

13. Shen Y, Silverstein JC, Roth S. In-hospital complications and mortality after elective spinal fusion surgery in the united states: a study of the nationwide inpatient sample from 2001 to 2005. J Neurosurg Anesthesiol. 2009;21(1):21-30. https://doi.org/10.1097/ANA.0b013e31818b47e9.

14. Memtsoudis SG, Kirksey M, Ma Y, et al. Metabolic syndrome and lumbar spine fusion surgery: epidemiology and perioperative outcomes. Spine (Phila Pa 1976). 2012;37(11):989-95. https://doi.org/10.1097/BRS.0b013 e31823a3a13.

15. Basques BA, Diaz-Collado PJ, Geddes BJ, et al. Primary and revision posterior lumbar fusion have similar short-term complication rates. Spine (Phila Pa 1976). 2016;41(2):E101-6. https://doi.org/10.1097/BRS.0000000000 001094.

16. Kreder HJ, Berry GK, McMurtry IA, Halman SI. Arthroplasty in the octogenarian: quantifying the risks. J Arthroplasty. 2005;20(3):289-93. https://doi. org/10.1016/j.arth.2004.09.024.

17. Koenig K, Huddleston JI 3rd, Huddleston H, Maloney WJ, Goodman SB. Advanced age and comorbidity increase the risk for adverse events after revision total hip arthroplasty. J Arthroplasty. 2012;27(7):1402-1407.e1 https://doi.org/10.1016/j.arth.2011.11.013.

18. Basques BA, Bell JA, Fillingham YA, Khan JM, Della Valle CJ. Gender differences for hip and knee arthroplasty: complications and healthcare utilization. J Arthroplasty. 2019;34(8):1593-1597.e1. https://doi.org/10. 1016/j.arth.2019.03.064.

19. Pulido L, Parvizi J, Macgibeny M, et al. In hospital complications after total joint arthroplasty. J Arthroplasty. 2008;23(6 Suppl 1):139-45. https://doi. org/10.1016/j.arth.2008.05.011.
20. Khatod M, Inacio M, Paxton EW, et al. Knee replacement: epidemiology, outcomes, and trends in Southern California: 17,080 replacements from 1995 through 2004. Acta Orthop. 2008;79(6):812-9. https://doi.org/10. 1080/17453670810016902.

21. Mahomed NN, Barrett J, Katz JN, Baron JA, Wright J, Losina E. Epidemiology of total knee replacement in the United States Medicare population. J Bone Joint Surg Am. 2005;87(6):1222-8. https://doi.org/10.2106/JBJS.D. 02546 .

22. Mendis S, Abegunde D, Yusuf S, et al. WHO study on Prevention of REcurrences of Myocardial Infarction and StrokE (WHO-PREMISE). Bull World Health Organ. 2005;83(11):820-9.

23. Joseph JR, Smith BW, Park P. Variability in standard outcomes of posterior lumbar fusion determined by national databases. World Neurosurg. 2017;97:236-40. https://doi.org/10.1016/j.wneu.2016.09.117.

24. Jain A, Hassanzadeh $H$, Puvanesarajah $V$, et al. Incidence of perioperative medical complications and mortality among elderly patients undergoing surgery for spinal deformity: analysis of 3519 patients. J Neurosurg Spine. 2017;27(5):534-9. https://doi.org/10.3171/2017.3.SPINE161011.

25. Pumberger M, Chiu YL, Ma Y, Girardi FP, Mazumdar M, Memtsoudis SG. National in-hospital morbidity and mortality trends after lumbar fusion surgery between 1998 and 2008. J Bone Joint Surg Br. 2012;94(3):359-64. https://doi.org/10.1302/0301-620X.94B3.27825.

26. Shultz BN, Bovonratwet P, Ondeck NT, Ottesen TD, McLynn RP, Grauer JN. Evaluating the effect of growing patient numbers and changing data elements in the National Surgical Quality Improvement Program (NSQIP) database over the years: a study of posterior lumbar fusion outcomes. Spine J. 2018;18(11):1982-8. https://doi.org/10.1016/j.spinee.2018.03.016.

27. Bemenderfer TB, Rozario NL, Moore CG, Karunakar MA. Morbidity and mortality in elective total hip arthroplasty following surgical care improvement project guidelines. J Arthroplasty. 2017;32(8):2359-62. https://doi.org/10.1016/j.arth.2017.02.080.

28. Bemenderfer TB, Rozario NL, Moore CG, Karunakar MA. Morbidity and mortality in elective total knee arthroplasty following surgical care improvement project guidelines. J Arthroplasty. 2016;31(9 Suppl):202-6. https://doi.org/10.1016/j.arth.2016.02.072.

29. Wolf BR, Lu X, Li Y, Callaghan JJ, Cram P. Adverse outcomes in hip arthroplasty: long-term trends. J Bone Joint Surg Am. 2012;94(14):e103. https:// doi.org/10.2106/JBJS.K.00011.

30. Beaulieu-Jones BK, Lavage DR, Snyder JW, Moore JH, Pendergrass SA, Bauer CR. Characterizing and managing missing structured data in electronic health records: data analysis. JMIR Med Inform. 2018;6(1):e11. https://doi.org/10.2196/medinform.8960.

\section{Publisher's Note}

Springer Nature remains neutral with regard to jurisdictional claims in published maps and institutional affiliations.
Ready to submit your research? Choose BMC and benefit from:

- fast, convenient online submission

- thorough peer review by experienced researchers in your field

- rapid publication on acceptance

- support for research data, including large and complex data types

- gold Open Access which fosters wider collaboration and increased citations

- maximum visibility for your research: over $100 \mathrm{M}$ website views per year

At BMC, research is always in progress.

Learn more biomedcentral.com/submissions 